\title{
Percentile analysis of plasma total bilirubin-How different will the rate of phototherapy for jaundice of neonates be by different standards?
}

\author{
Yoshiro Nagao $^{1,2}$, Hiroshi Watanabe ${ }^{1,3}$, Syun-ichiro Yokota ${ }^{1,4}$ \\ ${ }^{1}$ Department of Pediatrics, Social Health Insurance Medical Center, Tokyo, Japan \\ ${ }^{2}$ Department of Pediatrics, The University of Tokyo, Tokyo, Japan \\ ${ }^{3}$ Department of Pediatrics, University Hospital Mizonokuchi, Teikyo University School of Medicine, Kawasaki, Japan \\ ${ }^{4}$ Yokota Children's Clinic, Odawara, Japan \\ Email: yn-nagao@pro.odn.ne.jp
}

Received 12 March 2012; revised 11 May 2012; accepted 24 May 2012

\section{ABSTRACT}

Phototherapy of a jaundiced neonate is usually started when bilirubin exceeds a threshold in the standard. There are several standards used in the developed countries even though the guideline of American Academy of Pediatrics is considered to be a global standard. Although the purpose of phototherapy is the prevention of kernicterus, nowadays the prevalence of kernicterus in otherwise healthy term neonates in the developed countries is rare. Meanwhile several potential adverse effects of phototherapy have been reported. In the present study we tried to estimate how different the rate of phototherapy for the jaundice of neonates at lower risk of kernicterus would be by different standards. For this purpose, we utilized the records of plasma total bilirubin (TB) values of 1893 healthy neonates of 38 weeks and more which were measured on day 6 for the percentile analysis. However, this database did not include the TB values of the neonates who received phototherapy by day 6 . Then the database was corrected with an assumption that TB on day 6 would have been normally distributed if no phototherapy had been performed. The mean and the standard deviation (SD) of corrected database were 11.29 mg/dl (193 $\mu \mathrm{mol} / \mathrm{l})$ and $3.63 \mathrm{mg} / \mathrm{dl}(62 \mu \mathrm{mol} / \mathrm{l})$, respectively. Using a standard distribution with these mean and SD, the percents of TB values which exceed 18.0, 19.0, 20.0 and $21.0 \mathrm{mg} / \mathrm{dl}$ on day 6 were estimated $3.22 \%$, $1.70 \%, 0.82 \%$ and $0.35 \%$, respectively. Results of the present report would help to estimate the relative rate of phototherapy that is performed for the neonates who are term and otherwise healthy by different standards.

Keywords: Neonatal Jaundice; Bilirubin; Phototherapy;
Kernicterus

\section{INTRODUCTION}

Neonatal jaundice is caused by plasma increase of unconjugated (indirect) bilirubin that occurs as results of excessive bilirubin production and delayed clearance of bilirubin from the blood. Although jaundice in the neonatal period is fundamentally harmless, some neonates need to be monitored because bilirubin is potentially toxic to the central nervous system. Elevated levels of plasma bilirubin, hyperbilirubinemia, can lead to bilirubin encephalopathy and subsequently kernicterus, with devastating, permanent neurodevelopmental handicaps.

There are two major treatments of hyperbilirubinemia: exchange transfusion and phototherapy. Exchange transfusion is performed for few neonates who are in a threatening condition of developing kernicterus. Meanwhile phototherapy is applied for much more neonates with less risk of kernicterus. Phototherapy of a jaundiced neonate is usually started when total bilirubin (TB) in the blood exceeds the threshold value in the standard. Various standards are used even among the developed countries [1]. Many of standards are categorized by gestational age including the guideline of American Academy of Pediatrics (AAP), because prematurity is one of a risk factors for kernicterus [2-6], and some standards are categorized by birth weight-for example the standards in Japan are all categorized by birth weight [7-9]. In the standards like Canadian guideline; low birth weight $(<2500 \mathrm{~g})$ is independently listed as a risk factor [5].

The rate of phototherapy is rather variable in the literatures [1,11-14]. But because neonatal jaundice is so common, many neonates at lower risk, most of whom will be unaffected, are treated to prevent kernicterus that would occur rarely [10]. Although reports of clinically 
significant adverse effects from phototherapy are rare, several possible side effects have been reported [15-18].

The purpose of the present study is to estimate how different the rate of phototherapy for the jaundice of the neonates at lower risk of kernicterus will be by different standards used in developed countries. For this purpose, we tried to perform a percentile analysis of TB.

\section{MATERIALS AND METHODS}

The definition of the neonates at lower risk of kernicterus as the participants in this study was according to the categorization of neonates in the guideline for phototherapy of AAP [6]. In this guideline, neonates at lower risk of kernicterus are defined as those whose gestational age are 38 weeks and more and who are not associated with any additional risk factors for kernicters, like isoimmune hemolytic disease, glucose-6-phosphate dehydrogenase deficiency, asphyxia, sepsis, acidosis, etc. So the neonates whose gestational ages were 38 weeks and more and who were not with any risk factors for kernicterus were chosen as the participants in this study.

In Social Health Insurance Medical Center, newborn infants usually stay at hospital for 6 days and more. A blood sampling for the screening of inherited metabolic disorders will be performed in principle on day 6 , otherwise on day 7 , and a plasma TB value is measured simultaneously. In the present report we used these data of plasma TB values on day 6 recorded between 1999 and 2008.

2618 neonates were born in our hospital from 1999 to 2007 , and the number of the neonates whose gestational ages were 38 weeks and more and who were not with any risk factors for kernicterus was 2279. In these 2279 neonates, 124 neonates received phototherapy by day 6 . Excluding these 124 neonates, blood samplings were performed for 1893 neonates on day 6 and for 262 neonates on day 7. Therefore we used 1893 data of TB measured on day 6 for the analysis.

TB was measured by optical density method using Bilmeter A (Mochida-Siemens, Tokyo, Japan).

Phototherapy used to be performed in our hospital by a standard that was established by modifying one of standards in Japan (Table 1) until 2007. As described above standards in Japan are categorized by the birth weight. The threshold TB values of the standard in our hospital shown in Table 1 were actually applied for 112 out of 124 neonates who received phototherapy and whose birth weights were more than $2500 \mathrm{~g}$. For the other 12 neonates whose birth weights were $2020-2474 \mathrm{~g}$, the lower TB values were applied as thresholds for phototherapy.

Statistical analyses were performed with a PC utilizing StatView ver. 5 (SAS Institute Japan, Tokyo, Japan). These analyses includes one-sample Kormogorov-Smirnov test to examine whether data are normally distributed.

This work was approved by institutional review board in Social Health Insurance Medical Center.

\section{RESULTS}

The histogram of TB data of 1893 neonates was shown in Figure 1. We named these data as database 1. The mean and the standard deviation (SD) of database 1 were $10.87 \mathrm{mg} / \mathrm{dl}(186 \mu \mathrm{mol} / \mathrm{l})$ and $3.25 \mathrm{mg} / \mathrm{dl}(55 \mu \mathrm{mol} / \mathrm{l})$, respectively. However, database 1 did not contain the TB data of the neonates who received phototherapy by day 6 to avoid the influence of phototherapy in the analysis. Then we tried to correct database 1 by adding the missing data which should have been included if no phototherapy had been performed until day 6 .

To correct database 1 we assumed that TB on day 6 would have been normally distributed if no phototherapy had been performed. First of all, we estimated the number of missing data. As described above, 124 out of 2279 neonates whose gestational ages were 38 weeks and more and who were otherwise healthy neonates received

Table 1. Standards of phototherapy for the neonates at lower risk of kernicterus in Japan (whose birth weights were $2500 \mathrm{~g}$ and more and who are not associated with any risk factors).

\begin{tabular}{lcccccc}
\hline \multicolumn{1}{c}{$\begin{array}{c}\text { Hour after birth } \\
\text { Day }\end{array}$} & $\begin{array}{c}24 \mathrm{~h} \\
48 \mathrm{~h}\end{array}$ & $72 \mathrm{~h}$ & $96 \mathrm{~h}$ & $120 \mathrm{~h}$ \\
\multicolumn{1}{c}{ Institute } & \multicolumn{5}{c}{ Threshold value (mg/dl) } \\
\hline Kobe University [7] & 10 & 12 & 15 & 18 & 18 \\
Our Hospital ( 2007) & 10 & 14 & 16 & 17 & 18 \\
Murata F [8] & 12 & 15 & 17 & 18 & 19 \\
The University of Tokyo [9] & 10 & 14 & 17 & 19 & 20 \\
\hline
\end{tabular}

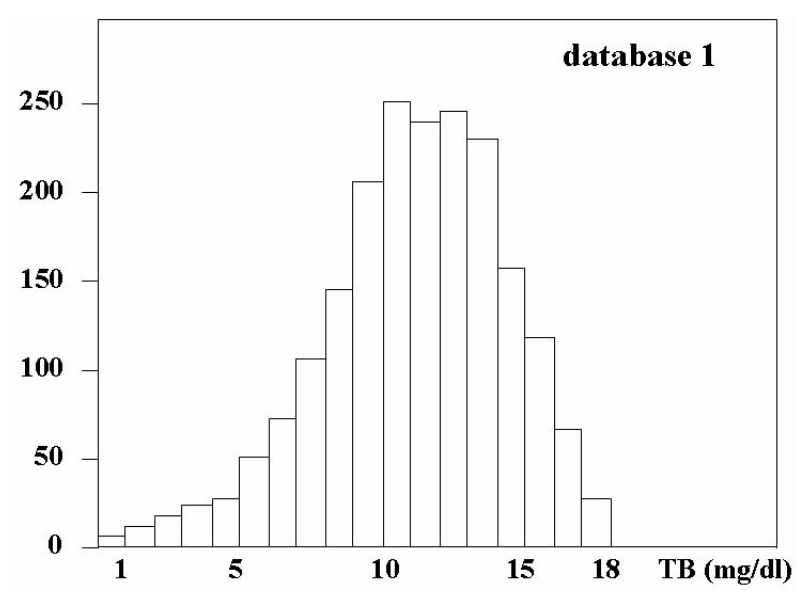

Figure 1. Histogram of TB on day 6 of the neonates whose gestational ages were 38 weeks and more and who are not associated with any risk factors for kernicterus (database 1). 
phototherapy by day 6 . Using these numbers we calculated that the rate of phototherapy for such neonates was $5.44 \%$. With an assumption that database 1 did not include $5.44 \%$ of higher TB data, the database 1 (1893 data) was considered to consist of $94.56 \%$ of the data of corrected database. Therefore the data number of corrected database and the number of missing data could be calculated 2002 and 109, respectively. Second, we estimated the mean of the corrected database. Database 1 should be missing the highest 109 TB data by phototherapy, so it is possible to calculate the approximate mean value by excluding the lowest 109 TB data from database 1 . We named such a database as database 2 , and the mean of database 2 was calculated as $11.29 \mathrm{mg} / \mathrm{dl}(193 \mu \mathrm{mol} / \mathrm{l})$. Third, to estimate missing highest 109 TB data, we calculated them with the following expression with an assumption that the distribution of TB values is symmetrical to the center value (the mean value).

$$
11.29 \times 2-\mathrm{TB}
$$

with the expression (1), the highest 109 TB data were calculated using the lowest $109 \mathrm{~TB}$ data, and 218 data that consisted of highest 109 TB data and lowest 109 TB data were named as database 2'. Finally, database 3 was established by adding database 2 and database 2'. As the matter of course the mean of database 3 was $11.29 \mathrm{mg} / \mathrm{dl}$, and the SD became $3.63 \mathrm{mg} / \mathrm{dl}(62 \mu \mathrm{mol} / \mathrm{l})$. To confirm that database 3 can be used for the percentile analysis, a one-sample Kormogorov-Smirnov test was performed for database 3, and there was no statistically significant difference between database 3 and the standard distribution that has same mean and SD as those of database 3 (p $=0.331)$. The calculating process was shown in Figure 2 .

The mean and the SD of corrected database can be calculated in different way by the lower 1001 TB data of database 1 (database 4). The highest TB data of database 4 was $11.3 \mathrm{mg} / \mathrm{dl}$. To estimate missing higher $1001 \mathrm{~TB}$ data, we calculated them with the following expression with an assumption that the distribution of TB values is symmetrical to the center value.

$$
11.30 \times 2-\mathrm{TB}
$$

Then database 5 was established by adding database 4 and the higher 1001 data calculated using the expression (2). The mean and SD of database 5 became to 11.30 $\mathrm{mg} / \mathrm{dl}$ and $3.63 \mathrm{mg} / \mathrm{dl}$, respectively. Bilmeter $\mathrm{A}$, with which we measured TB, can display the data of TB to the first place of a decimal point. Therefore the means of database 3 and database 5 are considered to be same, and SD of them was also same so far calculated (Figure 2).

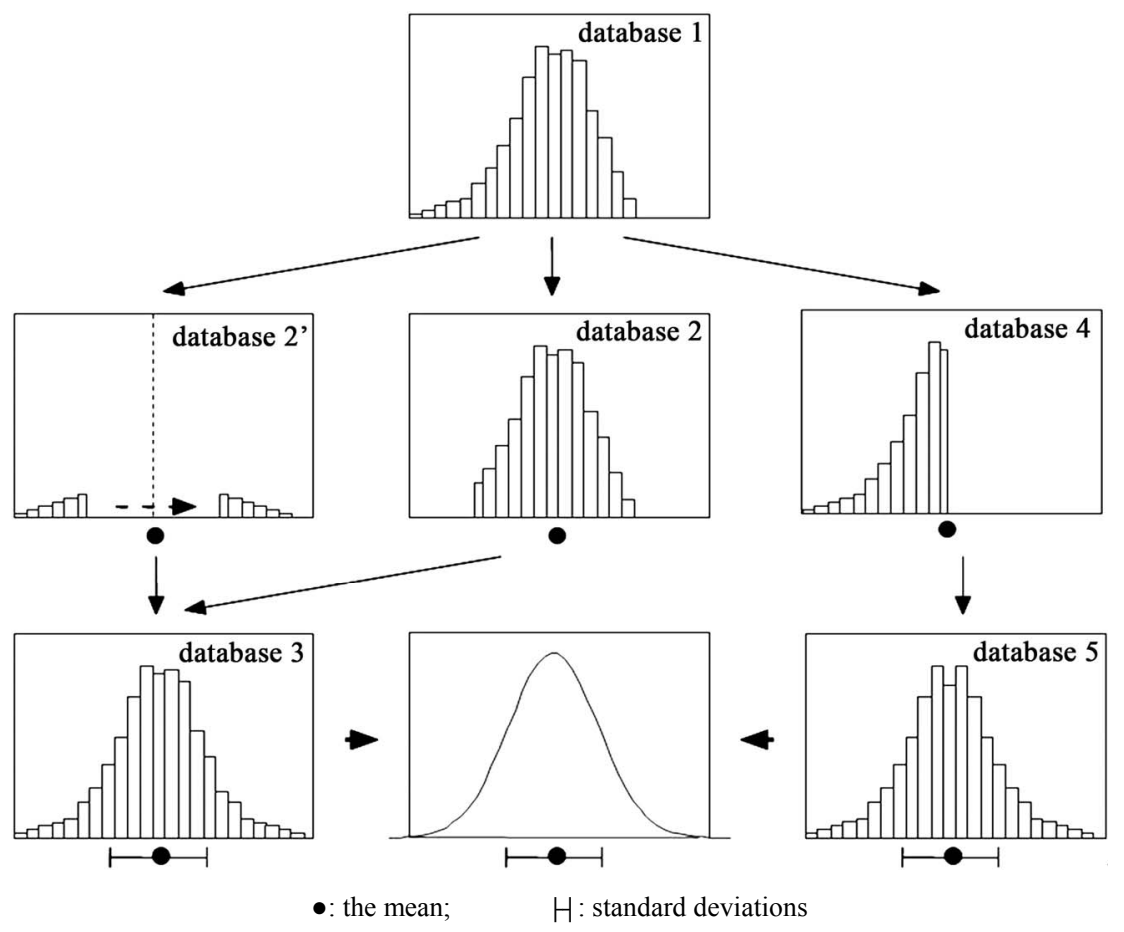

Database 1: Raw histogram of 1893 TB data. Database 2: The histogram that does not contains the lowest 109 data of database 1. Database 2': The histogram that consists of the lowest 109 data of database 1 and the 109 data which are calculated by the expression $(11.29 \times 2-$ TB) with the lowest 109 data. Database 3: The histogram that is established by adding database 2 and database 2'. Database 4: The histogram that consists of the lower 1001 data of database 1. Database 5: The histogram that consists of 1001 data of database 4 and the 1001 data which are calculated by the expression $(11.30 \times 2$ - TB) with the 1001 data of database 4 .

Figure 2. Calculating process of corrected database. 
Using a standard distribution that has same mean and SD as those of database 3 , the percents of TB values which exceed 18.0, 19.0, 20.0 and $21.0 \mathrm{mg} / \mathrm{dl}(308,325$, 342 and $359 \mu \mathrm{mol} / \mathrm{l}$ ) on day 6 were estimated $3.22 \%$, $1.70 \%, 0.82 \%$ and $0.35 \%$, respectively.

\section{DISCUSSION}

The rate of phototherapy is rather variable in the reported studies [1,11-14]. It depends on how high the general level of bilirubin of the studied neonates was, how bilirubin was measured, and what kind of a standard for phototherapy was used. Although AAP guideline is considered to be a global standard, the evidence base for any standards of phototherapy is weak and various standards are used as national guidelines even among the developed countries (Table 2) [2-6]. In Japan no guideline has been established, and several standards are used (Table 1) [7-9]. We used to have our own standard in our hospital until 2007, however, the rate of phototherapy was so high that we changed our standard to Murata's standard in 2008 (Table 1).

Phototherapy is believed to be a convenient and safety treatment of neonatal jaundice; however, several possible side effects have been reported. One hazard which had concerned investigators was the possibility of retinal damage to infants exposed to phototherapy [15]. This hazard is now avoided by attaching neonates with an eye-musk. Reported cutaneous side effects include transient rashes and the uncommon bronze baby syndrome, and a more hazardous side effect is ultraviolet burn [16]. Recent study suggested that intensive phototherapy might increase the number of atypical melanocytic nevi identified at school age [17]. The potential of phototherapy to damage DNA based on animal or cell-culture studies have been described, and one study suggests that phototherapy increases DNA damage also in human newborns [18].

The purpose of the present study was to estimate how different the rate of phototherapy for the jaundice of the

Table 2. Guidelines of phototherapy for the neonates at lower risk of kernicterus in the Western world (whose gestational ages were 37 or 38 weeks and more and who are not associated with any risk factors).

\begin{tabular}{lcccccc}
\hline \begin{tabular}{c} 
Hour after birth \\
\multicolumn{1}{c}{ Day }
\end{tabular} & & $\begin{array}{c}24 \mathrm{~h} \\
\text { Country }\end{array}$ & $\begin{array}{c}48 \mathrm{~h} \\
\text { Establish }\end{array}$ & \multicolumn{5}{c}{ The } & Day 3 & Day 4 & Day 5 & Day 6 \\
\hline Israel [2] & 2008 & 10 & 14 & 16 & 17.5 & 18.5 \\
South Africa [3] & 2006 & 10 & 14 & 16.5 & 18 & 18.5 \\
Canada [4] & 1999 & 10 & 15 & 18 & 19 & 19 \\
UK [5] & 2010 & 11.5 & 14.5 & 17.5 & 20.5 & 20.5 \\
USA [6] & 2004 & 12 & 15 & 17.5 & 19.5 & 21 \\
\hline
\end{tabular}

neonates at lower risk of kernicterus would be by different standards. For this purpose we utilized recorded data of plasma TB values on day 6. It is usual to let the neonates stay in the hospital for 6 days and to perform blood sampling for the screening of inherited metabolic disorders on day 6 in Japan. And we have measured plasma TB simultaneously on day 6 since 1999. These are the reason why we arbitrary chose the plasma TB measured on day 6 in the present report. Although there are several assumptions in the present study, the results suggest that when a threshold TB value on day 6 is elevated by 1 $\mathrm{mg} / \mathrm{dl}$ the percent of neonates whose TB values exceed the threshold on day 6 will become approximately half.

The actual rate of phototherapy for the neonates at lower risk of kernicterus in our hospital was 5.44\%, however, the results of percentile analysis indicated that the percent of TB values which exceeded $18.0 \mathrm{mg} / \mathrm{dl}$ that is a threshold value on day 6 for a neonate at lower risk was $3.22 \%$. One possible cause of this discrepancy is that the neonates at lower risk of kernicterus defined in the analysis contained those whose birth weights were less than $2500 \mathrm{~g}$. Actually 12 neonates received phototherapy by the lower thresholds of TB. To examine the influence of these neonates, we performed another analysis for the neonates whose birth weights were $2500 \mathrm{~g}$ and more, who are categorized into neonates at lower risk in Japanese standards. The actual rate of phototherapy of such neonates was $5.61 \%$ and the result of analysis indicated that the percent of TB values which exceeded $18.0 \mathrm{mg} / \mathrm{dl}$ for such neonates was $3.40 \%$. Therefore an influence of the neonates of lower birth weights $(<2500 \mathrm{~g})$ on the result of analysis seems little. Meanwhile the discrepancy may be related to the natural course of neonatal jaundice. The lower percent of TB which exceeds 18.0 $\mathrm{mg} / \mathrm{dl}$ in the percentile analysis suggests that TB values on day 6 of some neonates who received phototherapy before day 6 might have become lower than $18.0 \mathrm{mg} / \mathrm{dl}$ if phototherapy had not been performed.

We should discuss the limitation of this study. First of all, calculated data are only TB measured on day 6 . Histograms of TB on another day should be different and the results of percentile analysis should be also different. Second, there are several ways to evaluate bilirubin value, bilirubin oxydase method, non-invasive transcutaneous method, to measure free bilirubin, etc. The results of percentile analysis should be different when bilirubin is measured by different methods. Third, we could not analyze the peak TB values of neonatal jaundice, and it is unable to compare the results of present study with other reports for peak TB values. Forth, we cannot predict the rate of phototherapy in the neonatal period pass by the calculated results in the present study.

Kernicterus is devastating neurological disorders which used to be a major cause of athetoid cerebral palsy. Al- 
though the prevalence of kernicterus in term infants is rare now, it is still being reported in North America and Western Europe in addition to less developed parts of the world [19]. However, in these countries, neonates stay at hospital only for few days, and it has been proposed that to search for validated criteria for follow-up of jaundiced infants after discharge are more important than revision of existing guideline for phototherapy [20].

As suggested in the present report the rate of phototherapy would be dependent on the stringency of standards. The Norwegian Pediatric Association established their national guideline in 2006. Recently, Bratlid et al. reported that with this guideline fewer babies in Norway received phototherapy and that no cases of chronic kernicterus have been reported since 2006 [21]. There is a possibility that the neonatal jaundice for otherwise healthy term neonates is being over-treated in the countries where stringent standards are used. Results of the present report would help to estimate the relative rate of phototherapy that is performed for the neonates who are term and otherwise healthy by different standards.

\section{REFERENCES}

[1] Hansen, T.W. (1996) Therapeutic approaches to neonatal jaundice: An international survey. Clinical Pediatrics, 35, 309-316. doi:10.1177/000992289603500604

[2] Kaplan, M., Merlob, P. and Regev, R. (2008) Israel guidelines for the management of neonatal hyperbilirubinemia and prevention of kernicterus. Journal of Perinatology, 28, 389-397. doi:10.1038/jp.2008.20

[3] Horn, A.R., Kirsten, G.F., Kroon, S.M., Henning, P.A., et al. (2006) Phototherapy and exchange transfusion for neonatal hyperbilirubinemia: Neonatal academic hospitallas' consensus guidelines for South Africa hospitals and primary care facilities. South African Medical Journal, 96, 819-824.

[4] The Canadian Paediatric Society (1999) Hyperbilirubinemia in term newborn infants. Canadian Family Physician, 45, 2690-2692.

[5] Rennie, J., Burman-Roy, S., Murphy, M.S. and Guideline Developmental Group (2010) Neonatal jaundice: Summary of NICE guidance. British Medical Journal, 340, c2409. doi:10.1136/bmj.c2409

[6] American Academy of Pediatrics Subcommittee on Hyperbilirubinemia (2004) Management of hyperbilirubinemia in the newborn infant 35 or more weeks of gestation. Pediatrics, 114, 297-316. doi:10.1542/peds.114.1.297

[7] Department of Pediatrics, Kobe University (1993) Management of premature and newborn infants. Nihon Iji
Shuppan, Tokyo, 205-222.

[8] Murata, F. (1981) Exchange transfusion and phototherapy. Syusanki Igaku, 11, 2059-2061.

[9] Igarashi, T. (2005) Manual for pediatric diseases. Chugai Igaku Sha, Tokyo, 564-567.

[10] Maisels, M.J. and McDonagh, A.F. (2008) Phototherapy for neonatal jaundice. New England Journal of Medicine, 358, 920-928. doi:10.1056/NEJMct0708376

[11] Eggert, L.D., Wiedmeier, S.E., Wilson, J. and Christensen, R.D. (2006) The effect of instituting a prehospital-discharge newborn bilirubin screening program in an 18-hospital health system. Pediatrics, 117, e855-e862. doi:10.1542/peds.2005-1338

[12] Bhutani, V.K., Johnson, L.H., Schwoebel, A. and Gennaro, S. (2006) A systems approach for neonatal hyperbilirubinemia in term and nearterm newborns. Journal of Obstetric, Gynecologic \& Neonatal Nursing, 35, 444455. doi:10.1111/j.1552-6909.2006.00044.x

[13] Maisels, M.J. and Kring, E.A. (1998) Length of stay, jaundice, and hospital readmission. Pediatrics, 101, 995998. doi:10.1542/peds.101.6.995

[14] Walsh, S.A. and Murphy, J.F. (2010) Neonatal jaundice-Are we over-treating? Irish Medical Journal, 103, 28-29.

[15] Dobson, V. (1976) Editorial: Phototherapy and retinal damage. Investigative Ophthalmology, 15, 595-598.

[16] Siegfried, E.C., Stone, M.S. and Madison, K.C. (1992) Ultraviolet light burn: A cutaneous complication of visible light phototherapy of neonatal jaundice. Pediatric Dermatology, 9, 278-282. doi:10.1111/j.1525-1470.1992.tb00348.x

[17] Csoma, Z., Hencz, P., Orvos, H., Kemeny, L., et al. (2007) Neonatal blue-light phototherapy could in-crease the risk of dysplastic nevus development. Pediatrics, 119, 10361037. doi: $10.1542 /$ peds.2007-0180

[18] Tatli, M.M., Minnet, C., Kocyigit, A. and Karadag, A. (2008) Phototherapy increases DNA damage in lymphocytes of hyperbilirubinemic neonates. Mutation Research, 654, 93-95.

[19] Maisels, M.J. (2010) Screening and early postnatal management strategies to prevent hazardous hyperbilirubinemia in newborns of 35 or more weeks of gestation. Seminar in Fetal \& Neonatal Medicine, 15, 129-135. doi:10.1016/j.siny.2009.10.004

[20] Bratlid, D. (2001) Criteria for treatment of neonatal jaundice. Journal of Perinatology Supplement, 1, S88-S92. doi:10.1038/sj.jp.7210656

[21] Bratlid, D., Nakstad, B. and Hansen, T.W. (2011) National guidelines for treatment of jaundice in the newborn. Acta Paediatrica, 100, 499-505. doi:10.1111/j.1651-2227.2010.02104.x 